\title{
Brief Probe into the Texture of Fabric Reconstruction in Fashion Design
}

\author{
Chunlan Huang \\ The Fashion Design and Management Branch \\ Jiangxi Institute of Fashion Technology \\ Nanchang, China \\ 2008huangcl@163.com \\ Ruijuan Ren \\ The Fashion Design and Management Branch \\ Jiangxi Institute of Fashion Technology \\ Nanchang, China \\ ranusren@hotmail.com
}

Keyword: Fashion; Fabric Reconstruction; Style; Redesign; Texture

\begin{abstract}
Fashion fabric reconstruction seems to be an indispensable element of fashion design. It should be focus on rich and abundant expressions of visual textures in the process of the apparel fabric redesign. People use various subtle techniques to generate the organization of the beauty in form, which create the unusual textures to improve the garment texture in details. Fabric reconstruction, called fabric redesign can renew the unattractive and simple garments in unique and innovative style that gives the fashion ready-to-wear variety of vivid, beautiful, original, captivating and stylish effects. This paper presents the major methods of the fabric reconstruction in fashion design realm, and introduces the multiple applications and effects of fabric design method of three dimensional modelling, addition and reduction visually, which especially illustrates the same method applied in the different fabrics to create vastly different design results, and even change, the entirely fabric construction for garments style.
\end{abstract}

\section{Introduction}

Fabric reconstruction is actually the new design on the garment materials, also known as the second design or redesign of the fabrics. This means that designers use various traditional crafts(drawn work, manual felt, shrink, embroidery, etc.) and high-tech ways (the computer-based embroidery, machine pleated technique, laser carving, hot iron flocking, punching and embossing and so on) to created the new surfaces with kaleidoscopic textures based on the pre-existing fabrics, that will generate the different visual effects and unique beauty. Fabric reconstruction is one of the favorite methods for fashion and textile designers, it can be fully expressed the designer's ideas and then to design different garments with different visual effects. Additionally, fabric redesign is a breakthrough in fashion design and also an important means to improve the quality of the clothes.

This article probes the changing relation between the fabric reconstruction and the different clothing materials, which combined with examples to discuss the design methods of the fabric reconstruction and the creative thinking.

\section{The Factors that Affect Textures in Fabric Reconstruction}

There are many factors influencing the style of the fabric. In this part, it emphatically analyses how the textures of fashion materials affect fabric reconstruction. Fabric textures are daedal because materials have different physical and chemical properties that are caused by the different effects on surface. Fabric textures are various nowadays through high-technologies to present diverse styles on the fabrics, such as thick fabric can make people feel steady, thin fabric has a kind of romantic and 
lightsome sense, hard fabric can make wearers look lean and handsome, rough fabric presents a feeling of nature and frankness. It can be seen, the fabric that might be thin or thick, soft or hard, fine or rough, lustrous or matt, how a designer seizes the fabrics to express the fashion style during the process of textile design? For example, there are some kinds of fabrics with gorgeous retro style that are taffeta, velvet, satin and hand embroidery fabric; on the other hand, georgette, chiffon, silk cotton, thin knitted fabric, lace and such fabrics are soft, smooth, and with strong drapability that will create a sense of ethereal romance; the fabrics with natural and simplicity style are generally cotton or sackcloth that is reflected in the rough and raw texture; the fabrics have Avant-garde style that can be lustrous coating fabrics and metallic fabrics, abstract pattern printed chemical fiber fabrics, mesh fabrics and all kinds of elastic knitting fabrics, which present a effect with modern-looking, scientific and technological sense. Today's China is an open country, in which information and communications technology develop rapidly; logistics are unobstructed; and also the growing competition emerges in fashion industry. Chinese designers are looking for their individual character and unique style to gain public acceptance in order to be different and create the visual aesthetic impact, or, to get a leg up on the competition, the designers transform the fabric to fully meet the current changes, more personalized and advancing demand. Thin or thick, soft or hard, fine or rough, lustrous or matt texture of the fashion materials can use fabric reconstruction to produce another kind of fabrics. Such as the thin silk and spun fabric can overlap to express hazy, implicative and abundance colour effects because of its high degree of transparency; on the other hand, denim can use the method of sequins embroidery, nail bead or other fabric reconstruction techniques to change the original straightforward style into a fair maiden look. Garment accessories are generally decoration materials can be used in fabric reconstruction. Now, with the development of science and technology, there are more and more accessories around us, such as all kinds of laces, sequins, rope lines, beads, shells, gemstones, zippers, ironwares, etc. These materials present the effects are also changing by the designer's collaging. It can be used for different fashion material through a lot of fabric reconstruction methods. We could use a lot of ways to implement our transformation of fabrics like plaiting, folding, embroidery, deconstruction, collage, piling up, hand weaving, laser engraved and so on. For example, how to make a piece of simplicity cotton fabric to be luxuriant? Designers use fabric reconstruction technique on this fabric, such as silk and beaded embroidery, then the luxuriant feel will be enhanced. If designers overlay the chiffon on the same cotton fabric, it will be immediately generating a sense of romance and elegance.

\section{Design Methods of Fabric Reconstruction}

2.5D Fabric Addition. The addition of the 2.5D fabric reconstruction is based on the printing and dyeing fabrics to add some decoration on the surface, which brings an embossed appearance of the objects. This kind of method is various that can be added beads, sequins, another fabric, diamonds, crystal materials small crafts, ropes, belts and such things on the fabric to make the appearance effects of the clothing more extravagant or stylish. For example, there are kinds of embroidery such like sequins embroidery, ribbon embroidery, beaded embroidery, and silk embroidery, etc. on the other hand, the suitable fabrics of the thin embroidery thread are generally thin cotton or silk fabrics that has a feeling of fine and fair; thick thread embroidery has a simple sense, generally we use thick woolen cloth; beaded fabrics have a luxuriant feeling, we can add the bead materials on a variety of fabrics, which have a very good effects. As shown in the Figure 1 is woolen yarn embroidery that brings a sense of strong and thick; Figure 2 shows the beaded on white satin that is elegant and noble; Figure 3 shows sequins embroidery, the big sequins are decorated on the knitting fabric, which brings magnificent stage presence for people; Figure 4 presents the thread embroidery that comes with an exquisite and delicate feeling, thread embroidery fall into two categories: machine embroidery and hand embroidery. The hand embroidery effects will be different from what the stitch of local characteristics is; generally, the hand embroidered is more delicate than machine embroidery for high-grade full dress. 
Fabric Reduction. The design method of fabric reduction can be gone through the dig, cut, hollowing, laser, tear, polish, devoré, fagoting and so on. It could make the vision of fabrics decreased and make the surface have a beauty of deformity with enlarged creativity. Digging and cutting clothing materials can easily make clothes elegant, stretch and thorough, but the untidy sense might follow. If we use this method, we should choose more professional fabrics that will not generate the raw edges to make sure the beauty of the garments. Tear and hollowing out fabrics can break the boring of the clothes with the penetrated visual effect. Drawn work shows more interesting appearance that mixed virtual reality. The method of reduction was a fashion trend during the 60s, 70 s and the designer at that time usually use this method to express the unique thoughts. For example, the Mother of Punk Vivienne Westwood who usually tore expensive material to express a weird type of beauty through creating a harmony colour blendent. Nowadays, fashion material reduction method is familiar and also one of the designer's favorite methods. They usually use digging, cutting, hollowing out and laser flowers, etc. As for Figure 5, it is collaging by treated bamboo material and transparent fabrics to generate a hollow out impression that are very ventilating. According to the Figure 6, the leather was cut into a small hole and adding some thong to decorate, this form makes the design more punk because of the luster of the material itself. As for Figure 7, we use laser to curve on the chiffon and make the fabric has a romantic quality. As shown in the Figure 8 , jean fabric used the way of drawn work to make it has the impression of abrade and become more individualistic and punkish.

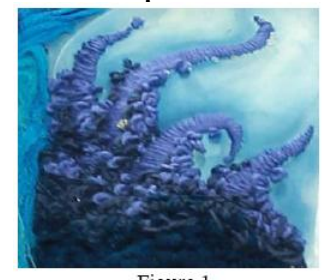

Figure $1_{-}$

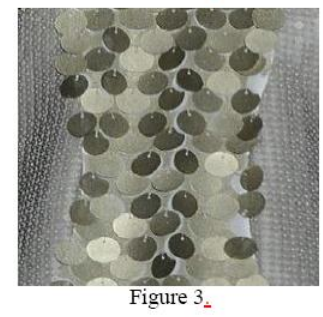

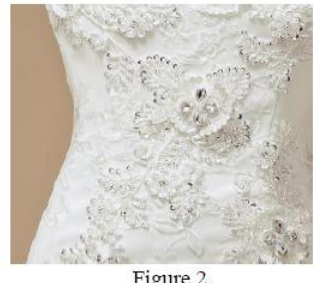

Figure 2,

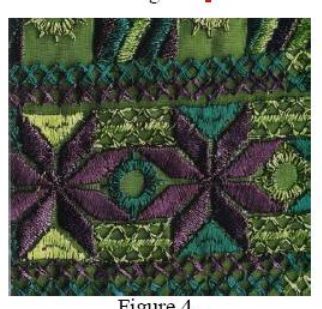

Figure 4.

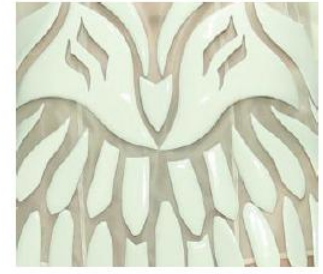

Figure 5,

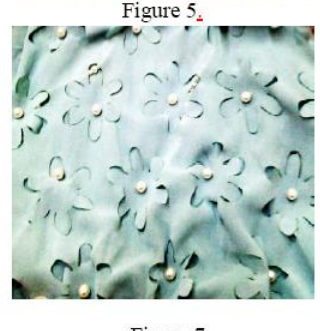

Figure 7.

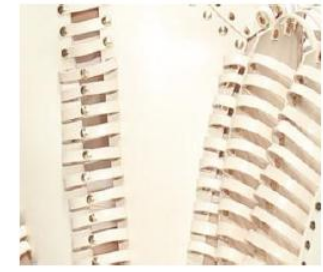

Figure 6.

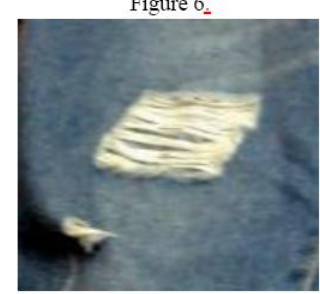

Figure 8

3D Modeling. Three-dimensional modelling method for fabric reconstruction is a fashion trend that is commonly seen in a lot of fashion shows recently, especially the design of the formal dress use most frequently. Stereo modelling method for fabric is mainly through various forms of craft technique to make the original plane state of fabrics to form solid shape. There exist many ways to achieve this kind f effect, generally the rouching (gathering stitch), pleating, contraction joint, overlay, filling and so on, which change the original surface state of the fabric to create a 3D effect. This method can enhance garment aesthetic, meanwhile that increase the sense of touch of the fabrics. For example: the tridimensional flower shaping is a design method of the recreation of textile with very strongly solid effect. The above "flower" actually does not mean that the real flowers of nature, it refers to the ornaments attached to the clothes. All kinds of fabrics, additionally, beads, ribbons, and such things can be used for overlay, which abide by the laws of formal beauty, and also different materials overlaying have different stacking effects. On the other hand, the 3D modelling method is different from the addition design on fabric, the latter is $2.5 \mathrm{D}$ spatial mode (embossed state); the same thing is they all increased quantity from the vision on the fabrics. As shown in Figure 9, a thin blended fabric with nylon wire overlock was processed into gradient after folding, which make the fabric has a delicate and romantic feeling and an upscale taste; Figure 10 shows a piece of magenta leather was cut into petals shape and pleated them first, then repeated overlay to bring a sense of enthusiasm; Figure 11 illustrates that the chiffon fabric was cut into a lot of square pieces and kept 
their raw edges to pleat and overlay at random, the resulting beauty of the fabric is easy, natural and casual; As the Figure 12 shows, this reconstructed fabric was to use crimped ribbons with stitching to form three-dimensional roses, the overall effect has elegant feeling because of the specific luster of the ribbons, and also has one of the noble style.
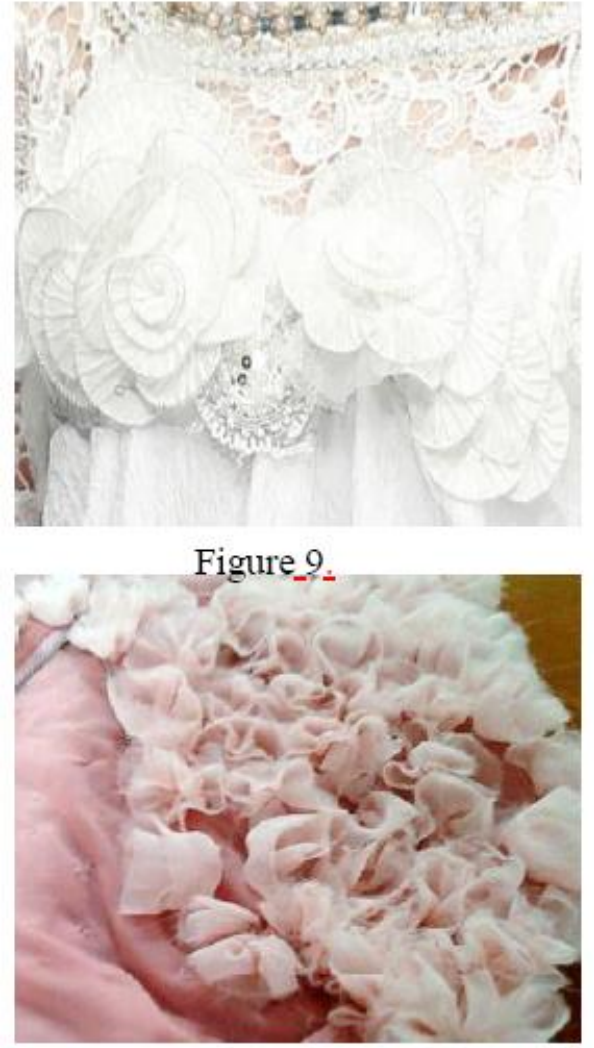

Figure 11.

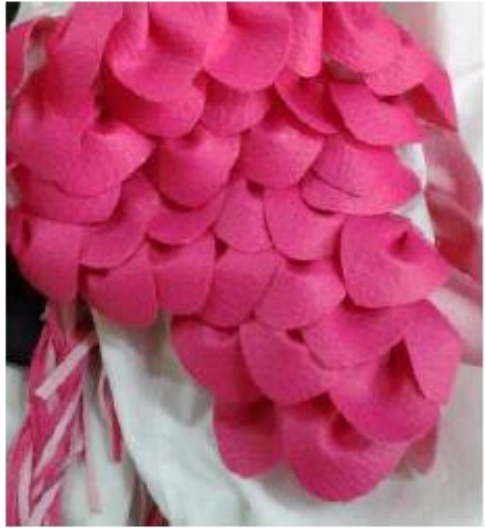

Figure 10

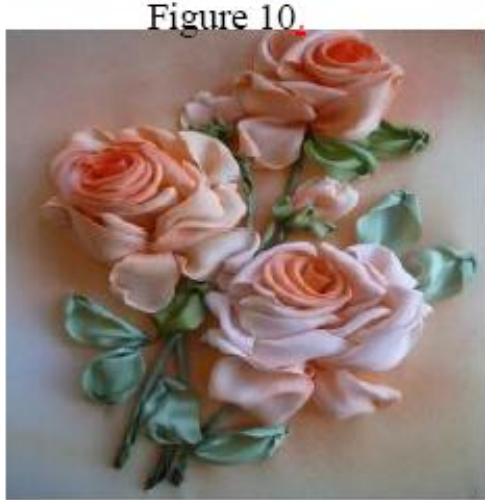

Figure12.

In many cases, these satisficed stereo effects can be achieved through many other forms of the 3D modelling such as pleating, smocking and so on. Different materials present different feelings. As shown in Figure 13, thin gauze was flat seamed and pleated and then joined the specific points abide by the rules of beauty in form, the smocking make the fabric look fine and elegant; Figure 14 shows buoyant application of edged oblique muslin flounces set in slightly carving rows spaced at random that make people have romantic and generous spirits; Figure 15 presents a smocking of a hemp fabric, which has a strong stereo effect, this kind of method make integral effect very pristine.

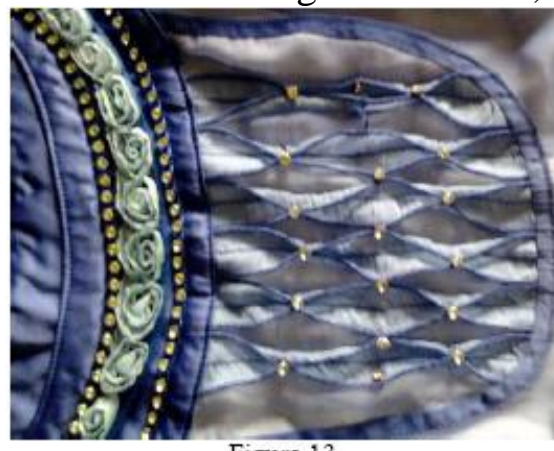

Figure 13.

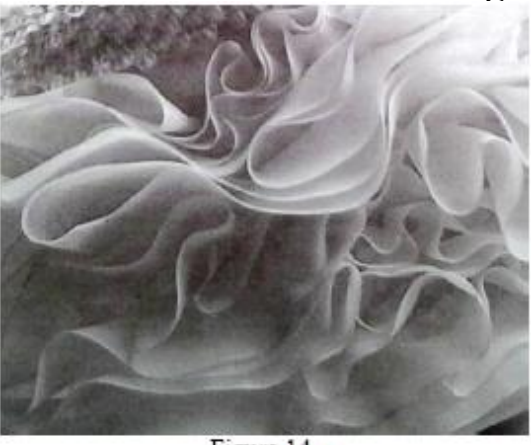

Figure 14,

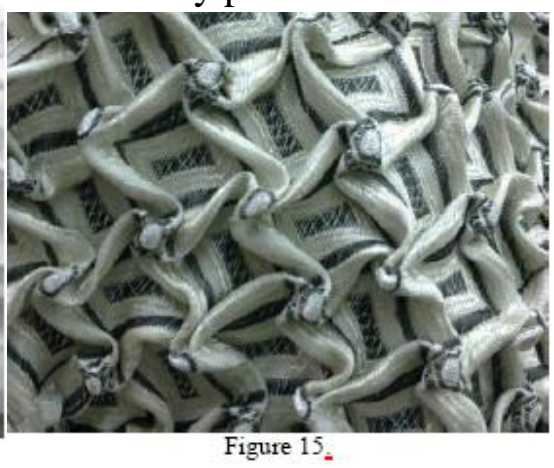

\section{Steps of Fabric Reconstruction in Fashion Design}

Preparation Stage. The first thing is to determine the theme. Designers should widely collect information on the subject, and choose some contents as inspiration. On the basis of extensive observation and consideration carefully, the data should be simplified and extracted from different 
angles, aspects, and colours, and then according to the principles of beauty in form, break up the order and reconstruct the structure to show these images from different means. As shown in Figure 16 , this designed fabric was inspired by blue and white porcelain and reconstructed with techniques of cut, paste, and embroidery.

Experimental Stage. In the Experimental stage, the first thing is to draw the sketch from inspirations, and then create the new work based on the pictures, after that, the designers should find the suitable fabrics according to the enlightenments from colors and textures of their design, and then use different techniques to empress the recreation effect. As shown in Figure 17, you should draw the sketch first, and then use different materials for the fabric samples, e.g. gauze can express the hazy feeling; woolen yarn can outline the simple of the lines, and luxuriant style can be satin to performance. Suppose the luxuriant fashion style is determined, the satin will be the one of the best choices for the sample of reconstructed fabric.

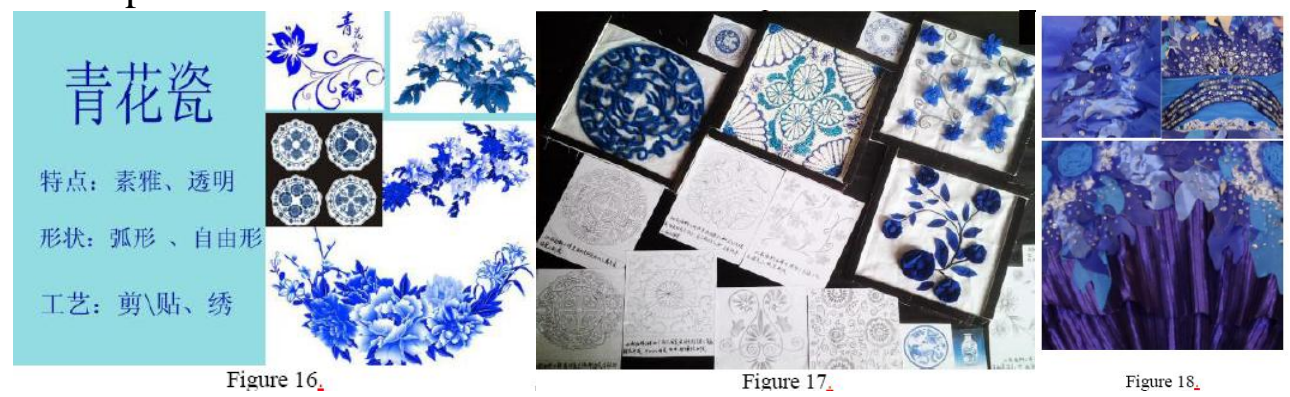

Final Stage. As above the satin fabric is suitable to express the gorgeous texture of reconstructed fabric, additionally, the luxuriant accessories can also support this kind of style in method, for example, you can find some pearls and crystals to arrange in specific order or at random on the fabric as shown in Figure 18, and Figure 19 illustrates the ready-to-wear garments made by this kind of reconstructed fabric. The process was to extract by the inspiration of blue and white porcelain, and abstracted the pattern to experiment, finally finished the garment.

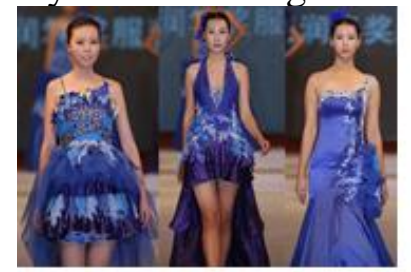

Figure 19 .

\section{Conclusion}

The specificity of different textiles has profound impact on the final outcome of any fabrics design. For example, the method of the $2.5 \mathrm{D}$ fabric reconstruction could have vastly different designs resulting from the types of the fabrics used and the design method employed. This method can be used in junction with the fabric reduction and the 3D modeling method to create holistic effects. Nowadays, fabric redesign is no longer limited to topical application, but rather applied throughout the entire garment. Fabrics design aims to recreate the look and feel of the fabrics to enhance its intrinsic beauty by ways of design and craftsmanship. The Design of garment fabric reconstruction, by definition is the recreation and redesign of the texture, colour, pattern and other observable outer characteristics in order to conform to the style of the design of the garment as well as to reinforce the uniqueness of the brand. Fabric redesign reinforces the importance of fabrics' role in fashion design and at the same time enriches the design process. Fabric reconstruction allows for more creativity and possibility that a designer could ever play with in their designs and hence cultivates much more variety and imagination in the world of fashion design. 


\section{References}

[1] L. Shi, "Resarch of Fabric Reconstruction”, Journal of Xi 'an Polytechnic University, Oct. 2010.

[2] A. Liu, "Discussion of Fabric Reconstruction Applied in the Trend of the Low-carbon Materials in Fashion Design", Value Engineering, 2012.

[3] M. Chen, “Application of Fabric Reconstruction in Fashion Design”, Journal of Ningde Normal University (Natural Science), vol. 1, Feb. 2011.

[4] J. Dou, "The Coordination of Formation and Fabric in Fashion Technological Design", Arts Education, 2013.

[5] R. Xu, "Fabric Creative Design”, Chemical Industry Press, Beijing, Nov. 2014.

[6] S. Xiu, "Creative Application of Fabric Reconstruction in Fashion Design”, Dazhongwenyi, 2011.

[7] L. Luo, "Application of Leather Fabric Reconstruction in Fashion Design", Leather Science and Engineering, Jan. 2014.

[8] W. Li, "Discussion of Application of Leather Fabric Reconstruction in Fashion Design", Knowledge Economy, 2013.

[9] B. Chen, Fashion Design, Donghua University Press, Apr. 2012.

[10] L. Wu, Dress Design and Three-dimensional Constitution, China Light Industry Press, Jul. 2011. 